\title{
RESPONSE FUNCTIONS FOR COMPUTING ABSORBED DOSE TO SKELETAL TISSUES FROM PHOTON IRRADIATION - AN UPDATE
}

\author{
Perry Johnson, MS, \\ Nuclear \& Radiological Engineering, University of Florida, Gainesville, FL 32611 \\ Amir Bahadori, MS, \\ Nuclear \& Radiological Engineering, University of Florida, Gainesville, FL 32611 \\ Keith Eckerman, PhD, \\ Life Sciences Division, Oak Ridge National Laboratory, Oak Ridge, TN 37831 \\ Choonsik Lee, PhD, and \\ Radiation Epidemiology Branch, National Cancer Institute, Bethesda, MD 20892 \\ Wesley E. Bolch, PhD \\ Nuclear \& Radiological / Biomedical Engineering, University of Florida, Gainesville, FL 32611
}

\section{Abstract}

A comprehensive set of photon fluence-to-dose response functions (DRFs) are presented for two radiosensitive skeletal tissues - active and total shallow marrow - within 15 and 32 bones sites, respectively, of the ICRP reference adult male. The functions were developed using fractional skeletal masses and associated electron absorbed fractions as reported for the UF hybrid adult male phantom, which in turn is based upon microCT images of trabecular spongiosa taken from a 40-year male cadaver. The new DRFs expand upon both the original set of seven functions produced in 1985, as well as a 2007 update calculated under the assumption of secondary electron escape from spongiosa. In the present study, it is assumed that photon irradiation of the skeleton will yield charged particle equilibrium across all spongiosa regions at energies exceeding 200 $\mathrm{keV}$. Kerma factors for active marrow, inactive marrow, trabecular bone, and spongiosa at higher energies are calculated using the DRF algorithm setting the electron absorbed fraction for selfirradiation to unity. By comparing kerma factors and DRF functions, dose enhancement factors and mass energy-absorption coefficient (MEAC) ratios for active marrow to spongiosa were derived. These MEAC ratios compared well with those provided by the NIST Physical Reference Data Library (mean difference of $0.8 \%$ ), and the dose enhancement factors for active marrow compared favorably with values calculated in the well-known study published by King and Spiers (1985) (mean absolute difference of 1.9 percentage points). Additionally, dose enhancement factors for active marrow were shown to correlate well with the shallow marrow volume fraction $\left(R^{2}=0.91\right)$. Dose enhancement factors for the total shallow marrow were also calculated for 32 bone sites

\section{Keywords}

bone dosimetry; dose-response function; active marrow; total shallow marrow

For reprints and correspondence contact: Wesley E. Bolch, PhD, PE, CHP Director, Advanced Laboratory for Radiation Dosimetry Studies (ALRADS) Department of Nuclear and Radiological Engineering University of Florida, Gainesville, Florida 32611-8300 Phone: (352) 846-1361 Fax: (352) 392-3380 wbolch@ufl.edu. 


\section{Introduction}

Dose response functions (DRFs) represent an advanced approach for calculating absorbed dose in anatomically complex tissue regions within the human skeleton. Originally developed by Keith Eckerman at Oak Ridge National Laboratory (Eckerman, 1985), these functions relate the absorbed dose in a skeletal target region, $D\left(r_{T}\right)$, to the photon fluence in a skeletal source region, $\Phi(E)$, and are primarily implemented using volume-averaged fluence estimates provided through Monte Carlo radiation transport within either a mathematical or voxel-based skeletal phantom. Dose response functions are unique in the way they decouple the transport of photons and their secondary electrons. During skeletal irradiation, photon interaction sites act as electron sources with energy distributions governed by the type of interaction and the energy of the incident photon. Once a secondary electron is liberated with a known kinetic energy, the situation is analogous to that encountered in internal dosimetry and can be treated as such by using pre-calculated electron absorbed fractions (AF). This situation is ideal for Monte Carlo dose reconstructions at diagnostic photon energies since computationally expensive secondary electron transport can be disabled, as it is already included in the pre-computed AF data. Another benefit of the DRF method is that absorbed fractions can be created using highly sophisticated methods specific to electron transport in bone. One example of this is the Paired Image Radiation Transport Code (PIRT) developed by researchers at the University of Florida which uses micro-CT images of the bone to derive absorbed fractions for different tissue regions (Shah et al., 2005). This type of detailed transport is not readily available within traditional Monte Carlo codes and anthropomorphic phantoms due to the microscopic size of the bone trabeculae and marrow cavities. ${ }^{1}$ Therefore, by using DRFs with bone specific AFs, a better dose estimate can be achieved when compared to traditional Monte Carlo codes with electron transport enabled.

Dose response functions can be created for a variety of source-target combinations. Target cells in the skeleton have been identified by the ICRP as being either the hematopoietic stem cells (for assessing leukemia risk) or the osteoprogenitor cells (for assessing bone cancer risk). In turn, the surrogate tissues within which these cells are thought to reside include active marrow (AM) and shallow marrow (all marrow found within 50 microns of the bone surface - $\mathrm{TM}_{50}$ ), respectively (ICRP, 2002, 2009). Source regions for photon interactions include active marrow (AM), inactive marrow (IM), and trabecular bone volume (TBV). As mentioned previously, whole-body anthropomorphic phantoms typically do not include explicit modeling of the bone trabeculae and marrow cavities. However, more advanced models do include a sub-segmentation of trabecular spongiosa and cortical bone; consequently, DRFs for different source regions can be combined to provide an absorbed dose to $\mathrm{AM}$ or $\mathrm{TM}_{50}$ per unit fluence in the spongiosa or medullary marrow (e.g., long bone shafts). The summation of AM, IM, and TBV source regions is made under the assumption that the fluence across the TBV, IM, and AM will be similar, which is appropriate for uniformly distributed heterogeneous mixtures. DRFs can further be combined to provide absorbed dose per unit fluence in fully homogenized bone (inclusive of cortical bone), but the assumption of a nearly uniform fluence is not as strong due to fluence depression across the bone cortex. Photon interactions within cortical bone are assumed to produce some secondary electrons that enter spongiosa or medullary marrow, but the energy they bring into these regions is assumed to be compensated for by secondary electrons leaving spongiosa at photon energies exceeding $200 \mathrm{keV}$.

\footnotetext{
${ }^{1}$ In the photon skeletal dosimetry studies of Kramer et al (2007), on-the-fly transport of secondary electrons in the bone microstructure is indeed performed, but due to array-size limitations, a greatly reduced presentation of bone trabeculae must be implemented, persevering only the marrow volume fraction, and not the true 3D geometry of the bone trabeculae and marrow cavities.
} 
While dose response functions offer an efficient and accurate method for calculating the dose to microscopically complex bone regions, there have been few updates to the initial set of functions produced in the mid-1980s. Since that time, two changes have occurred which need to be considered in any new calculational set. First, the surrogate tissue regions defining the location of the osteoprogenitor cells has changed from the trabecular and cortical endosteal layers of ICRP Publications 26 and 30 (ICRP, 1977, 1980). The new surrogate tissue, termed total shallow marrow in this study, now includes marrow tissues within $50 \mu \mathrm{m}$ of the bone surfaces (trabecular and inner cortical of the long-bone shafts), and is no longer considered within the osteons of cortical bone (e.g., cortical bone is no longer a target tissue in the ICRP system) (ICRP, 2009). Second, more advanced methods have been developed to assemble AF data in the skeletal tissues. Traditional methods for determining skeletal absorbed fractions relied on sampling of linear path-length distributions obtained from 2D optical scans of trabecular bone (Darley, 1972; Beddoe et al., 1976; Whitwell, 1973). This approach was used in the initial $1985 \mathrm{DRF}$ release where AF data were derived for only seven bone sites and only for active marrow (Eckerman, 1985). As mentioned previously, new techniques as used in the PIRT method go a step further by tracking electrons within a 3D micro-CT dataset for nearly every bone site of interest. These scans provide a more complete description of the bone micro-architecture while also quantifying cortical bone, trabecular bone, and marrow volume fractions. These fractions have be used to develop a set of reference masses which are directly related to the calculated AFs (Hough et al., submitted).

An interesting extension of DRFs is the calculation of kerma factors for different components of bone. By setting the AF for self-irradiation to unity and the AF for all other source regions to zero, secondary electrons created during photon interactions will deposit their energy locally thus providing an approximation of the kerma for a specified bone component or tissue region. Kerma factors can be created for different components based on the masses and mass attenuation coefficients used. As an example, factors can be created for $\mathrm{AM}$, IM, total marrow $(\mathrm{TM}=\mathrm{AM}+\mathrm{IM})$, or spongiosa $(\mathrm{SP}=\mathrm{AM}+\mathrm{IM}+\mathrm{TBV})$. Kerma factors are closely related to the 3 -factor method, which has been used in the past to estimate dose to active and shallow marrow (Lee et al., 2006). The method, shown as equation (1), begins with an approximation of the energy deposited in homogenized bone (ideally homogenized spongiosa) and adds correction factors to adjust for the fraction of active marrow found in the homogenized region, the enhanced photoelectric absorption of photons in mineral bone at low energies, and resultant enhancement of marrow dose by these photoelectrons as they enter the adjacent marrow cavities. The first two factors are realized simply as the fractional mass of active marrow in the homogenized region, $\mathrm{r}_{\mathrm{AM}}$, and as the ratio of the mass-energy absorption coefficients (MEAC) of AM to that of homogenized tissue, $\left(\mu_{\mathrm{en}} / \rho\right)_{\mathrm{AM}} /\left(\mu_{\mathrm{en}} / \rho\right)_{\mathrm{SP}}$. The third factor, also called the dose enhancement factor, $\mathrm{S}\left(\mathrm{E}_{\mathrm{ph}}\right)$, is more complex, as it relates to the size and shape of the trabeculae microstructure and is thus bone-site specific.

$$
\text { Energy }_{\mathrm{AM}}=\text { Energy }_{\mathrm{SP}} \mathrm{r}_{\mathrm{AM}}\left[\frac{\mu_{\mathrm{en}}}{\rho}\right]_{\mathrm{SP}}^{\mathrm{AM}} \mathrm{S}\left(\mathrm{E}_{\mathrm{ph}}\right)
$$

The most extensive set of photon skeletal dose enhancement factors was published in 1985 by researchers at the University of Leeds (King and Spiers, 1985). In this work, lithium fluoride $(\mathrm{LiF})$ powder was introduced into the marrow cavities of three lumbar bone specimens each having a different trabecular bone volume fraction. Percent excess dose was calculated by comparing the dose to $\mathrm{LiF}$ inside the marrow cavities to the dose to $\mathrm{LiF}$ outside the influence of the bone microarchitecture. These results were then extended to other bone sites through theoretical derivations dependent on the path-length through the 
marrow cavities. Measured path-length distributions from the three samples were compared to distributions found in literature and a table of AM enhancement factors for seven bone sites and three different ages was compiled. For the past 25 years, this table has represented the most complete set of dose enhancement factors and has been used by several researchers to calculate active marrow dose [see reviews in (Xu and Eckerman, 2009)].

As shown in equation (2), the 3-factor method can be rewritten in terms of dose by dividing through by the mass of active bone marrow in the specified skeletal site (factor one):

$$
\operatorname{Dose}_{\mathrm{AM}}=\operatorname{Kerma}_{\mathrm{SP}}\left[\frac{\mu_{\mathrm{en}}}{\rho}\right]_{\mathrm{SP}}^{\mathrm{AM}} \mathrm{S}\left(\mathrm{E}_{\mathrm{ph}}\right)
$$

Kerma factors can be used in combination with dose response functions to mimic this formulation for both active and shallow marrow. Under conditions of charged particle equilibrium, the ratio of energy absorption coefficients for two different tissues is equivalent to a ratio of the collisional kerma tabulated in each tissue. This can be seen in equations 3 and 4, as the MEAC ratio (factor two) has been replaced by the ratio of kerma factors for the tissues of interest. Assuming then the dose-response function provides the most accurate assessment of marrow dose, the enhancement factor is provided by the ratio of the DRF to kerma for the respective target tissue.

$$
\begin{aligned}
\operatorname{Dose}_{\mathrm{AM}} & =\operatorname{Kerma}_{\mathrm{SP}}\left[\frac{K_{\mathrm{AM}}}{K_{\mathrm{SP}}}\right]\left[\frac{D R F_{\mathrm{AM}}}{K_{\mathrm{AM}}}\right] \\
\operatorname{Dose}_{\mathrm{TM}_{50}} & =\operatorname{Kerma}_{\mathrm{SP}}\left[\frac{K_{\mathrm{TM}}}{K_{\mathrm{SP}}}\right]\left[\frac{D R F_{\mathrm{TM}_{50}}}{K_{\mathrm{TM}}}\right]
\end{aligned}
$$

Thus, by using the DRF approach, both the ratio of mass energy absorption coefficients and the dose enhancement factor can be derived in an alternate fashion.

In this study, a comprehensive set of photon fluence-to-dose response functions have been developed using skeletal electron AF data calculated from micro-CT images of a 40-yearold male cadaver and skeletal sites with the UF adult male hybrid phantom (Hough et al., submitted). These functions represent an update to the work previously published by Eckerman et al. (2008) who used similar data derived from a 66-year-old male cadaver. In the previous study, AF data were used which incorporated both electron escape from spongiosa and electron cross-fire from the surrounding cortical bone. These assumptions have come into question and are discussed further in this paper. The new DRFs are presented here for multiple bone sites for both $\mathrm{AM}$ and $\mathrm{TM}_{50}$ target regions. This work is further expanded to include $\mathrm{AM}$ and $\mathrm{TM}_{50}$ dose enhancement factors for each spongiosa region of the adult male skeleton.

\section{Methods and Materials}

The algorithm for calculating fluence-to-dose response functions is shown below.

$$
\frac{D\left(r_{T}\right)}{\Phi(E)}=\sum_{S} \frac{m\left(r_{S}\right)}{M\left(r_{T}\right)} \sum_{i} \int_{0}^{E_{\max }} \phi\left(r_{T} \leftarrow r_{S}, E_{i}\right)(i / \rho)_{r_{S}} n_{r_{S}}\left(E_{i}\right) E_{i} d E_{i}
$$


In this equation, $m\left(r_{S}\right)$ and $m\left(r_{T}\right)$ are the masses of the source and target regions, $\varphi\left(r_{T} \leftarrow r_{S}\right.$, $\left.E_{i}\right)$ is the absorbed fraction from region $S$ to region $T$ for electrons of energy $E_{i},(i / \rho) r_{S}$ is the mass attenuation coefficient of region $S$, with $\mathrm{i}=\tau, \sigma, \kappa$, and $v$ indicating one of four process including photoelectric, Compton scattering, pair-production in the nuclear field or pair-production in the electric field, and $n_{r S}\left(E_{i}\right) E d E_{i}$ denotes the number of electrons between $E$ and $E+d E_{i}$ released by process $i$ within region $S$. In this research, an in-house MATLAB $^{\mathrm{TM}}$ code was written to evaluate equation (5). The code works by iterating first through each source region, and second through each interaction type. The integration of equation (5) is handled numerically when the energy distribution of secondary electrons is continuous. This is the case for Compton scattering, pair and triplet production, where the Klein-Nishina relationship is used to describe the energy spectrum of the former and spectra for pair and triplet production are based upon a uniform distribution from zero up to their respective maximum energies. Mass attenuation coefficients for mineral bone, active marrow, and inactive marrow were evaluated using the National Institute of Standards and Technology's (NIST) Physical Reference Data Library (Hubbell and Seltzer, 2004). Elemental compositions for each bone component were taken from ICRP Report 89 (ICRP, 2002).

As mentioned previously, absorbed fraction and mass ratios were derived from micro-CT images of a 40-year-old male cadaver where 32 bone sites (including symmetric duplicates) were harvested, cored, and scanned (Hough et al., submitted). These micro-CT images were used within PIRT, along with macro-images of bone sites taken from the UF reference adult male hybrid phantom, to track electrons as they entered, exited, and traveled within the trabecular micro-structure. The AF data was originally developed for use in internal dosimetry applications where beta particles emitted from bone-seeking radionuclides impart energy to active and shallow marrow. This situation is fundamentally different than the photon dosimetry case due to the fact that electrons are being produced only in specific skeletal locations. Thus, a high-energy beta particle emitted from mineral bone which escapes the bone macro-structure may not be compensated for by a beta particle produced in the surrounding soft tissue. In the internal dosimetry case, this leads to a reduction in active and shallow marrow dose at high energies. For dose response functions, the assumption is that electrons will be created throughout the tissues, and at higher energies, will be created with roughly the same probability in bone as in the surrounding soft tissues. Accordingly, a high-energy electron which escapes the bone macro-structure is likely to be compensated for by an electron created in the surrounding soft tissue, setting up dynamic charged particle equilibrium.

In order to provide DRFs under this assumption, a forced convergence was enacted whereby the DRFs were matched with a kerma approximation at $200 \mathrm{keV}$. At this energy the DRFs are already shown to converge with kerma coefficients before decreasing further due to the energy escape for spongiosa-generated secondary electrons. This energy cutoff has also been noted in literature as both the ratio between the mass-energy absorption coefficients and the experimentally derived dose enhancement factors tend toward unity after $200 \mathrm{keV}$ (King and Spiers, 1985; Kramer et al. 2003). Kerma factors for the three basic skeletal components (active marrow, inactive marrow, and mineral bone) were calculated using equation (5) and setting the AF for self-irradiation to unity for all energies. Kerma factors for total marrow, also representing kerma factors for shallow marrow, were calculated by multiplying $\mathrm{K}_{\mathrm{AM}}$ and $\mathrm{K}_{\mathrm{IM}}$ by their respective mass fractions for each bone site and taking their sum. This is shown as equation (6), where $C F$ is the cellularity factor in the second formulation:

$$
K_{T M}=\frac{m_{A M}}{m_{T M}} K_{A M}+\frac{m_{I M}}{m_{T M}} K_{I M}=C F[\rho]_{A M}^{T M} K_{A M}+(1-C F)[\rho]_{I M}^{T M} K_{I M} .
$$


Kerma factors for spongiosa were also calculated in this way where the kerma factor for total marrow and trabecular (or mineral) bone were multiplied by their respective mass fractions for each bone site and then summed. This is shown as equation (7), where MVF and BVF are acronyms for marrow and bone volume fractions:

$$
K_{S P}=\frac{m_{T M}}{m_{S P}} K_{T M}+\frac{m_{T B}}{m_{S P}} K_{T B}=M V F[\rho]_{T M}^{S P} K_{T M}+B V F[\rho]_{T B}^{S P} K_{T B} .
$$

Dose enhancement factors and MEAC ratios were derived for each spongiosa region of the adult male skeleton using equations (3) and (4) given above.

\section{Results}

The 32 bone sites included in this study can be classified into three groups: (1) spongiosa sites with active marrow; (2) spongiosa sites without active marrow; and (3) medullary marrow within the shafts of the long bones. Spongiosa sites with active marrow include the axial skeleton, the proximal femur, and the proximal humerus. Spongiosa sites without active marrow include the distal humerus and femur, the proximal and distal ends of all other arm and leg bones, the patella, the feet and ankles, and the hands and wrists. While these sites have no active marrow, they do contain an endosteal layer which houses the osteoprogenitor cells and are thus significant for dose reconstruction. Fluence-to-dose response functions have been calculated for a photon energy range between $10 \mathrm{keV}$ and 10 $\mathrm{MeV}$. Table 1 lists DRFs for bone sites with active marrow as the target. The functions are arranged for a spongiosa source where DRFs for trabecular bone, active marrow, and inactive marrow sources have been combined. The DRFs are implemented by taking the product of the DRF and the volume-averaged fluence within a given spongiosa region. Thus, the units for the functions are absorbed dose per unit fluence $\left(\mathrm{Gy} \mathrm{m}^{2}\right)$. Tables 2,3 , and 4 list all DRFs having $\mathrm{TM}_{50}$ as a target. Additional AM targets are given in Table 4 for the upper halves of the femur and humerus shafts where some active marrow resides in the reference adult (Hough et al., submitted). The tables have been separated by bone group in order to make them more concise. While Tables 2 and 3 provide dose per fluence in spongiosa regions of the skeleton, Table 4 lists DRFs per fluence in the medullary marrow of the long bone shafts.

Calculated dose enhancement factors and MEAC ratios are given in Tables 6 to 10. These values were derived according to equations (3) and (4) where kerma factors for the primary spongiosa components, as shown in Table 5, were calculated using equation (5). Kerma factors for total marrow and spongiosa were then calculated using equations (6) and (7). The calculated MEAC ratios are compared to MEAC ratios determined from the NIST Physical Reference Data Library (Hubbell and Seltzer, 2004). Elemental compositions for each spongiosa site were calculated based on mass fractions taken from the UF adult male reference phantom, and elemental compositions of the primary spongiosa components as listed in ICRP Report 89 (ICRP, 2002). Beyond this study, these values represent a robust set of bone-site specific spongiosa elemental compositions which may be used as material inputs during Monte Carlo simulation. These values are listed in Table 3 of Hough et al (submitted) along with their associated densities. The percent difference between NIST MEAC ratios and those calculated in this study were very low. The largest percent difference was $4.4 \%$ for the cranium at the lowest calculated energy. The average percent difference for each bone site and all energies was approximately $0.8 \%$. 


\section{Discussion}

In addition to numerical ratios, the relationship between kerma and absorbed dose can be observed by plotting the DRF and kerma factors on the same axis. Figure 1 exhibits these energy-dependent functions for the cranium where kerma factors for active marrow, total marrow, trabecular bone, and spongiosa have been graphed alongside DRFs for active and shallow marrow. As seen in Figure 1, $\mathrm{DRF}_{\mathrm{AM}}$ converges to $\mathrm{K}_{\mathrm{AM}}$ at low energies as the absorbed fraction $\varphi(\mathrm{AM} \leftarrow \mathrm{AM})$ approaches unity at low energies, and the corresponding absorbed fractions $\varphi(\mathrm{AM} \leftarrow \mathrm{IM})$ and $\varphi(\mathrm{AM} \leftarrow \mathrm{TB})$ approach zero. This phenomenon is seen in most bone sites where any residual differences are less than $1 \%$. Another interesting feature is the location of each curve within the energy range of diagnostic photons. In Figure $1, \mathrm{~K}_{\mathrm{TB}}$ represents an upper dose limit and $\mathrm{K}_{\mathrm{TM}}$ represents a lower dose limit for photon energies below $200 \mathrm{keV}$. These curves highlight two different ways to estimate the absorbed dose in spongiosa: either by assuming it is fully mineral bone or is fully total marrow (leading to overestimates and underestimates, respectively, in the active marrow dose). If the tissue composition of spongiosa is available, as provided in this study, spongiosa kerma values can be calculated using a Monte Carlo transport code and a computational phantom with a sub-segmented skeleton. As shown earlier, the ratio between the $\mathrm{K}_{\mathrm{AM}}$ or $\mathrm{K}_{\mathrm{TM}}$ curves and the $\mathrm{K}_{\mathrm{SP}}$ curve explicitly provides an estimate the MEAC ratio, and the ratio between the $\mathrm{DRF}_{\mathrm{AM}}$ or $\mathrm{DRF}_{\mathrm{TM} 50}$ curves and those for $\mathrm{K}_{\mathrm{AM}}$ or $\mathrm{K}_{\mathrm{TM}}$ provide estimates of the dose enhancement factor.

Also shown in Figure 1 is $\mathrm{DRF}_{\mathrm{AM}}$ calculated under the previous assumption of electron escape from spongiosa. This approach was taken by Eckerman et al. (2008) for all bone sites using AF data originally calculated for internal dosimetry applications. The phenomenon of electron escape was also noted in an earlier study by Lee et al (2006) which used the original 1985 DRFs (Eckerman, 1985) to calculate absorbed dose from an external photon sources. In that study, absorbed dose was shown to decrease at high energies due to electrons migrating out of the skeletal site. Here, the 1980's AF data was based on an infinite spongiosa which did not include electron escape. However, because the bone sites were irradiated in a vacuum in the study of Lee et al (2006), no consideration was given for electrons created in the surrounding soft tissue. The CSDA ranges of electrons in cortical bone and soft tissue at energies of $1 \mathrm{MeV}$ to $10 \mathrm{MeV}$ are 2 to $28 \mathrm{~mm}$ and 4 to $48 \mathrm{~mm}$, respectively. Consequently, it is likely that extra-skeletal electrons will be able to cross a cortical shell of approximately $2-5 \mathrm{~mm}$ thickness. Another complicating factor is the direction of the incident beam. The thickness of the cortical shell in this direction can change depending on positioning in the photon field, especially for flat bones. Due to this uncertainty, the recommendation of this study is to use $\mathrm{K}_{\mathrm{SP}}$ to estimate skeletal tissue doses at photon energies exceeding $200 \mathrm{keV}$. This is a realistic, albeit conservative approach, as it assumes dynamic charged particle equilibrium has been established.

Dose enhancement factors are plotted in Figures 2 and 3 for $\mathrm{AM}$ and $\mathrm{TM}_{50}$ targets, respectively, and are expressed as percent excess dose. In Figure 2, several bone sites which displayed similar enhancement are combined by showing only their mean and one standard deviation. Dose enhancement factors for AM are highest for the cranium and cervical vertebra, and are lowest for the proximal humerus and mandible. As marrow dose enhancement is related to electrons produced in trabecular bone, it was expected that bones with smaller marrow cavities would display a greater degree of dose enhancement. To test this theory, shallow marrow volume fractions (as a percentage of total marrow volume, SMVF\%MV) were compared for the 13 bone sites of Group 1 as shown in Table 11 (Hough et al., submitted). The correlation between $\mathrm{SMVF}_{\% \mathrm{MV}}$ and dose enhancement in $\mathrm{AM}$ is strong with a calculated $\mathrm{R}^{2}=0.91$. These results are intuitive as bone sites with a higher $\mathrm{SMVF}_{\% \mathrm{MV}}$ have a larger percentage of active marrow within the range of secondary 
electrons produced in the trabecular bone volume. Dose enhancement was also shown to correlate well with the trabecular bone volume fraction (as a percentage of total spongiosa, $\mathrm{TBVF}_{\% \mathrm{SP}}$ ) with a calculated $\mathrm{R}^{2}$ value of 0.82 . This correlation follows from the fact that as marrow cavities get smaller, the $\mathrm{TBVF}_{\%} \mathrm{SP}$ typically increases.

A similar analysis was performed for the $\mathrm{TM}_{50}$ dose enhancement factors shown graphically in Figure 3. While the data displayed the same general trend when plotted versus photon energy, no simple correlation was found with any mass or volume fraction. Here, it is evident that multiple factors played a role in determining the amount of dose enhancement in shallow marrow which may include the size and shape of the marrow cavities, the thickness of the trabeculae, and the overall amount of trabecular bone in each skeletal site.

In order to further validate the results of this study, AM dose enhancement factors were compared with published factors given by King and Spiers (1985). Figure 4 shows this comparison for the cranium, cervical vertebrae, and proximal femur. As can be seen in the figure, the dose enhancement factors from this study track well with data from the earlier study. A maximum difference of 4.1 percentage points was found for the cranium at peak enhancement, and the average difference for all bone sites (seven included) and energies was found to be only 1.9 percentage points. The strong agreement provides at least ancillary evidence that the results of this study can be applied across different phantoms. While individual bone sites may vary in the amount of AM, IM, and TBV, DRFs are based on mass ratios which assumingly are less variable across different models. To add a level of specificity for a given phantom, the three-factor method can be applied using the enhancement factors provided in this study. In this way, the MEAC ratios can be selected based on the unique skeletal composition of the individual phantom. In the end regardless of what phantom is used, the DRFs and enhancement factors provided in this study were derived using ICRP compliant reference masses and should be applicable in a majority of situations where reference phantoms are used to determine dose to active and shallow marrow.

\section{Conclusions}

In this study, a comprehensive set of fluence-to-dose response functions have been calculated for 32 different bone sites. The functions have been assembled in tabular format and are intended for use in Monte Carlo studies as a way to estimate dose to both the active and shallow marrow. The new DRFs update and expand upon the original functions which incorporated less sophisticated AF data and only a limited number of bone sites. The new DRFs also update a preliminary set of DRFs published in 2008 which applied AF data without adjusting for the unique circumstances of irradiation by high-energy photons. As presented in this study, a realistic, yet conservative estimate for this situation is to apply DRFs at energies below $200 \mathrm{keV}$, and use a kerma approximation thereafter. In addition to dose-response functions, MEAC ratios and dose enhancement factors have been calculated according to the formulation of the three-factor method. The MEAC ratios were shown to compare well with those determined from the NIST Physical Reference Data Library (Hubbell and Seltzer, 2004), and the enhancement factors for active marrow were shown to compare well with the semi-experimental study of King and Spiers (1985).

The information presented in this study provides the researcher two ways to calculate skeletal absorbed dose. First, DRFs can be applied directly using fluence estimates tallied within the spongiosa region of a sub-segmented skeleton. Using this method, data from Table 3 of Hough et al (submitted) can be used to assess bone-specific elemental compositions for spongiosa, and a either a tally multiplier or post-processing can be used to translate fluence to dose. The second method is to apply the three-factor formula and 
incorporate bone-specific enhancement factors. As mentioned previously, this method can be applied when the skeletal composition is assumed to differ greatly from the composition used in this study. Both methods represent a practical approach for estimating absorbed dose in the complex regions of the human skeleton. Future studies will concentrate on the application of these methods across different phantoms, and will investigate the results in comparison with previous techniques.

\section{Acknowledgments}

This research was supported in part by grants R01 CA116743 and R01 CA96441 with the National Cancer Institute, and by grant DE-FG07-06ID14773 with the US Department of Energy.

\section{References}

Beddoe AH, Darley PJ, Spiers FW. Measurements of trabecular bone structure in man. Phys. Med. Biol. 1976; 21:589-607. [PubMed: 972924]

Darley, PJ. Department of Medical Physics. University of Leeds; Leeds, UK: 1972. An investigation of the structure of trabecular bone in relation to the radiation dosimetry of bone-seeking radionuclides.; p. 231

Eckerman, KF. Aspects of the dosimetry of radionuclides within the skeleton with particular emphasis on the active marrow.. In: Schlafke-Stelson, AT.; Watson, EE., editors. Proceedings of the Fourth International Radiopharmaceutical Dosimetry Symposium. Oak Ridge Associated Universities; Oak Ridge, Tennessee: 1985. p. 514-534.

Eckerman KF, Bolch WE, Zankl M, Petoussi-Henss N. Response functions for computing absorbed dose to skeletal tissues for photon irradiation. Radiat. Prot. Dosim. 2008; 127:187-191.

Hough M, Johnson P, Rajon D, Jokisch D, Lee C, Bolch WE. An image-based skeletal dosimetry model for the ICRP reference adult male - internal electron sources. Phys Med Biol. submitted.

Hubbell, J.; Seltzer, S. [September 13, 2005] Tables of x-ray mass attenuation coefficients and mass energyabsorption coefficients (Version 1.4) [Online]. 2004. http://physics.nist.gov/zaamdi

ICRP. ICRP Publication 26: Recommendations of the International Commission on Radiological Protection. Pergamon, Oxford: 1977.

ICRP. International Commission on Radiological Protection. Oxford, UK: 1980. ICRP Publication 30: Limits for intakes of radionuclides by workers.

ICRP. ICRP Publication 89: Basic anatomical and physiological data for use in radiological protection - reference values. Ann ICRP. 2002; 32:1-277.

ICRP. ICRP Publication 110: Adult reference computational phantoms. Ann ICRP. 2009; 39:1-165.

King SD, Spiers FW. Photoelectron enhancement of the absorbed dose from X rays to human bone marrow: experimental and theoretical studies. Br J Radiol. 1985; 58:345-356. [PubMed: 4063677]

Kramer R, Khoury HJ, Vieira JW, Kawrakow I. Skeletal dosimetry for external exposure to photons based on microCT images of spongiosa from different bone sites. Phys Med Biol. 2007; 52:66976716. [PubMed: 17975292]

Kramer R, Vieira JW, Khoury HJ, Lima FR, Fuelle D. All about MAX: a male adult voxel phantom for Monte Carlo calculations in radiation protection dosimetry. Phys Med Biol. 2003; 48:12391262. [PubMed: 12812444]

Lee C, Lee C, Shah AP, Bolch WE. An assessment of bone marrow and bone endosteum dosimetry methods for photon sources. Phys Med Biol. 2006; 51:5391-5407. [PubMed: 17047259]

Shah AP, Bolch WE, Rajon DA, Patton PW, Jokisch DW. A paired-image radiation transport model for skeletal dosimetry. J Nucl Med. 2005; 46:344-353. [PubMed: 15695796]

Whitwell, JR. Department of Medical Physics. University of Leeds; Leeds, UK: 1973. Theoretical investigations of energy loss by ionizing particles in bone.; p. 268

$\mathrm{Xu}, \mathrm{XG}$.; Eckerman, KF. Handbook of anatomical models for radiation dosimetry. Taylor \& Francis; London, UK: 2009. 


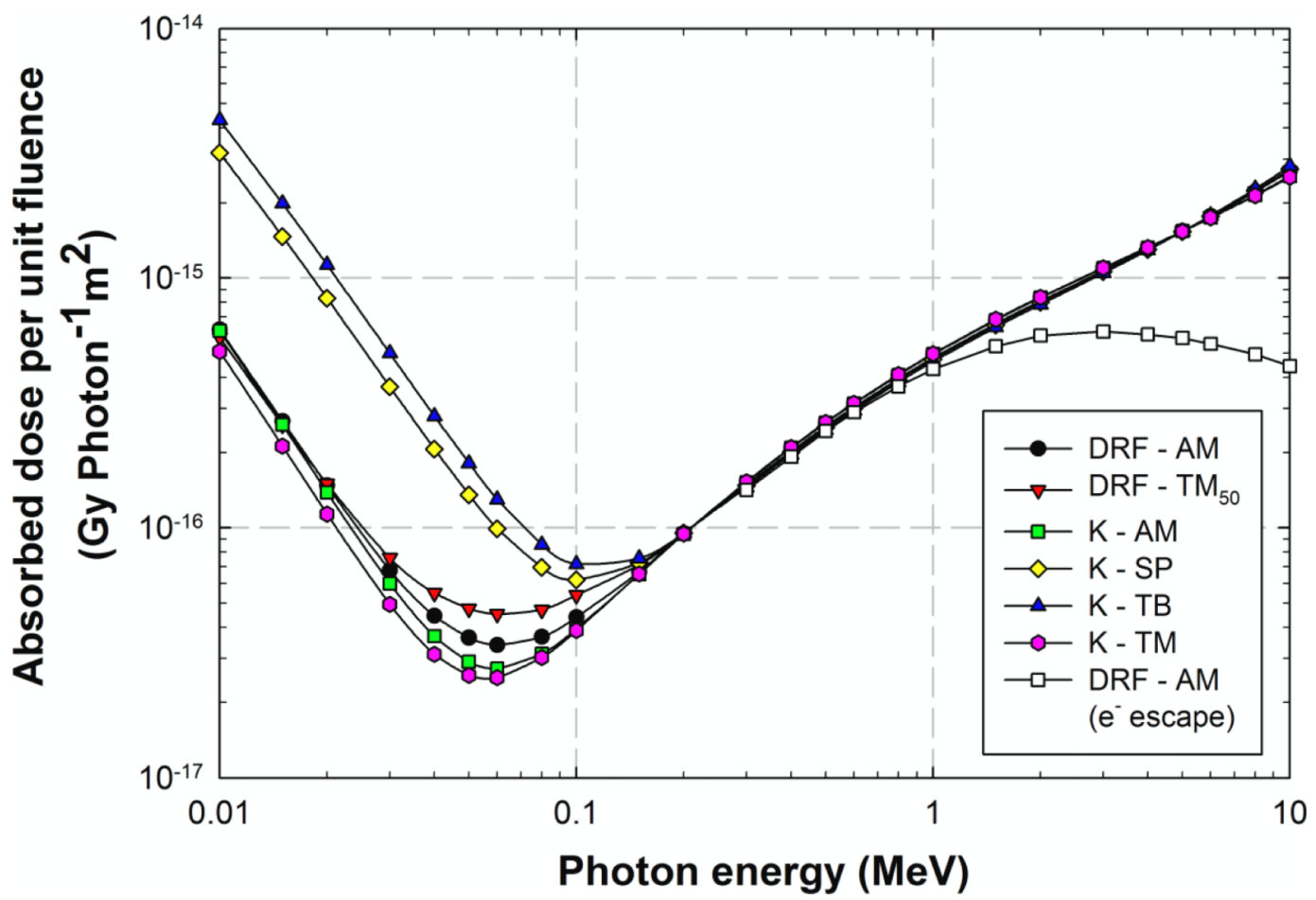

Figure 1.

Dose response functions and kerma factors for the cranium in the adult male. 


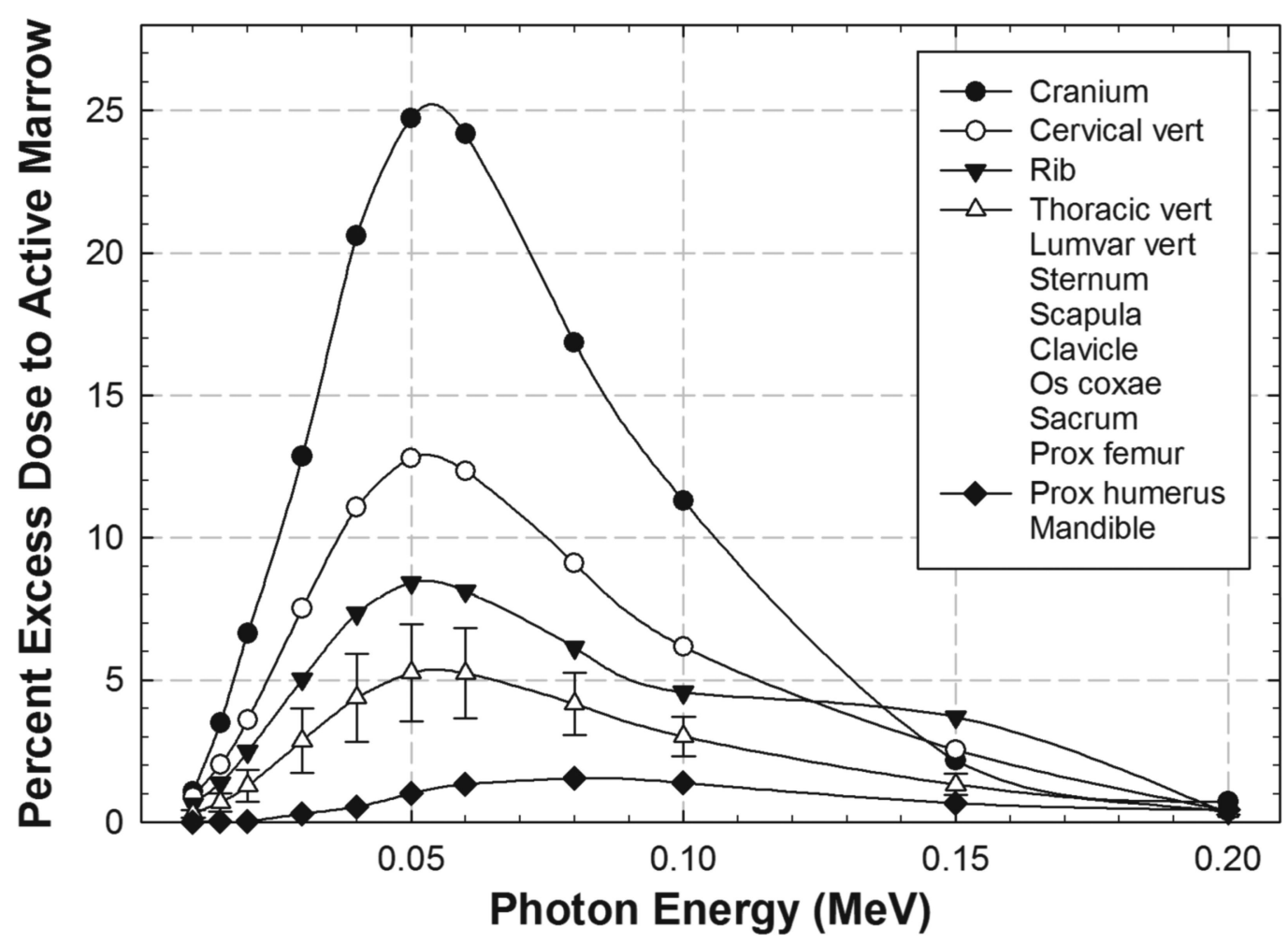

Figure 2.

Dose enhancement factors in active marrow calculated as the ratio of $\mathrm{DRF}_{\mathrm{AM}}$ to $\mathrm{K}_{\mathrm{AM}}$, and formulated as percent excess dose $\left(\mathrm{DRF}_{\mathrm{AM}}-\mathrm{KAM}\right) / \mathrm{K}_{\mathrm{AM}} \times 100$. The error bars indicate the standard deviation of the grouping of bones consisting of the thoracic vertebra, lumbar vertebra, sternum, scapula, clavicle, os coxae, sacrum, and proximal femur. 


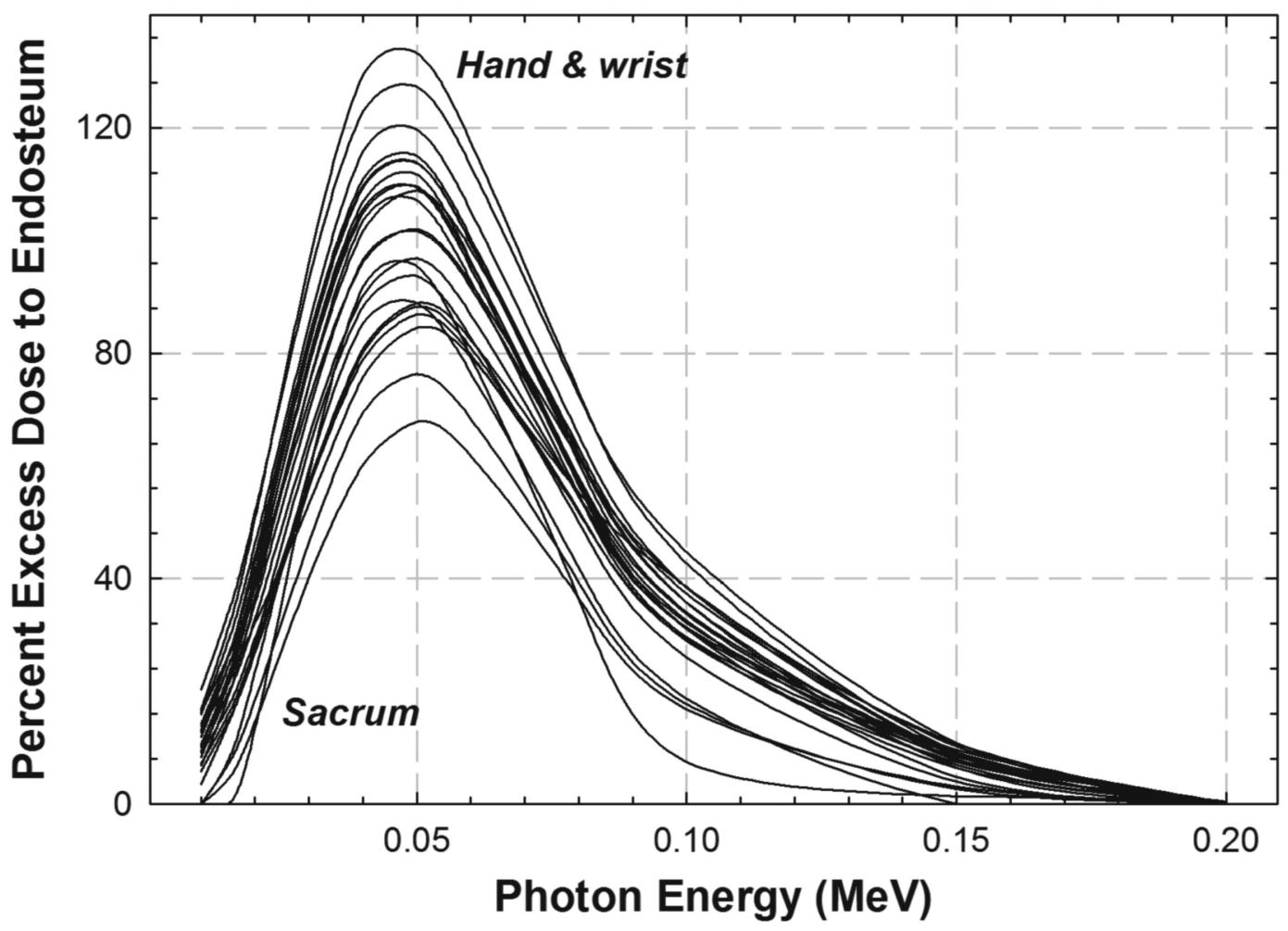

Figure 3.

Dose enhancement factors in shallow marrow calculated as the ratio of $\mathrm{DRF}_{\mathrm{TM} 50}$ to $\mathrm{K}_{\mathrm{TM}}$, and formulated as percent excess dose $\left(\mathrm{DRF}_{\mathrm{TM} 50}-\mathrm{K}_{\mathrm{TM}}\right) / \mathrm{KTM} \times 100$. 


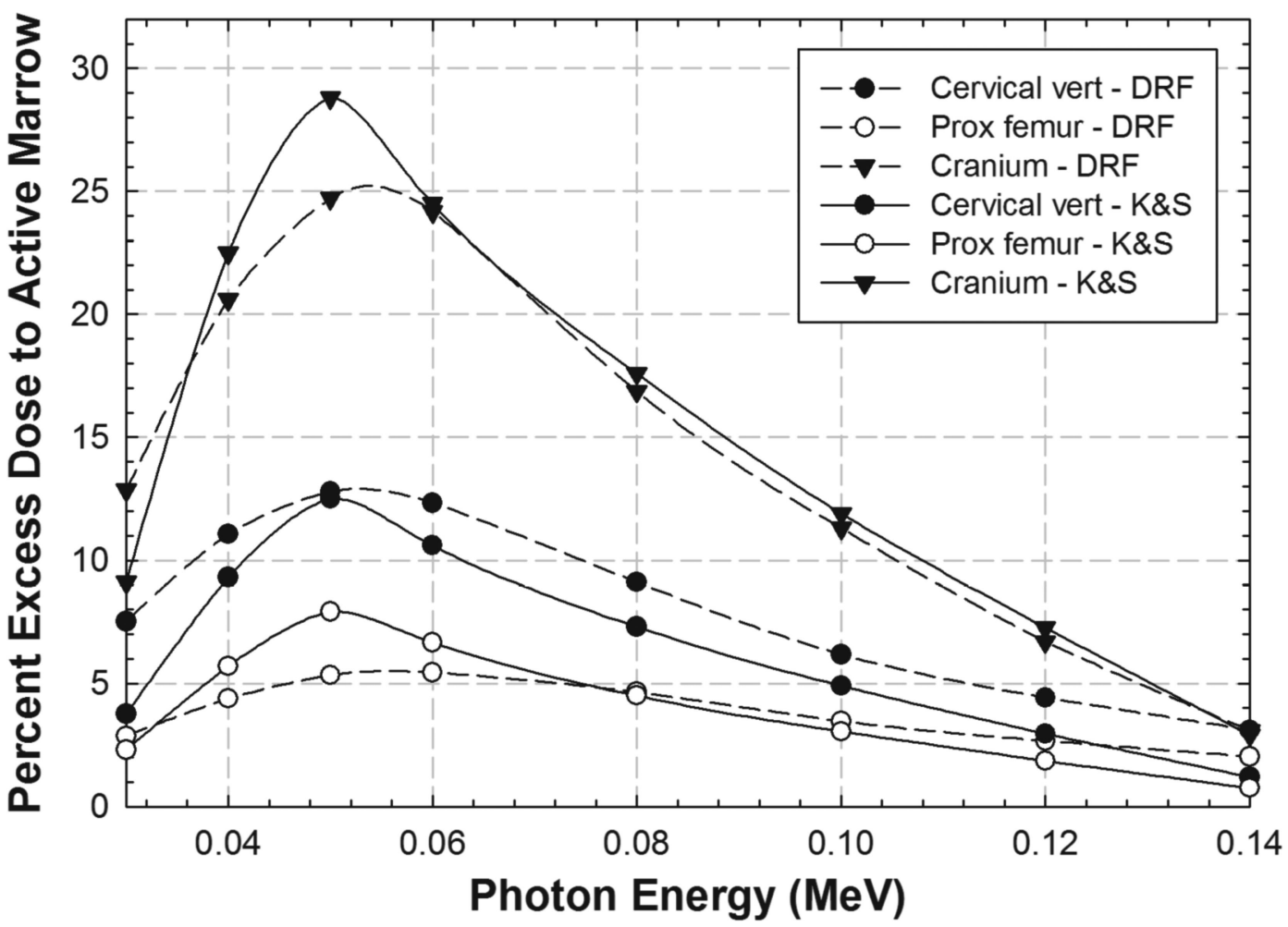

Figure 4.

Dose enhancement in active marrow for the cranium, cervical vertebra, and proximal femur. Calculated values from this study are compared to values published by King and Spiers (1985). 


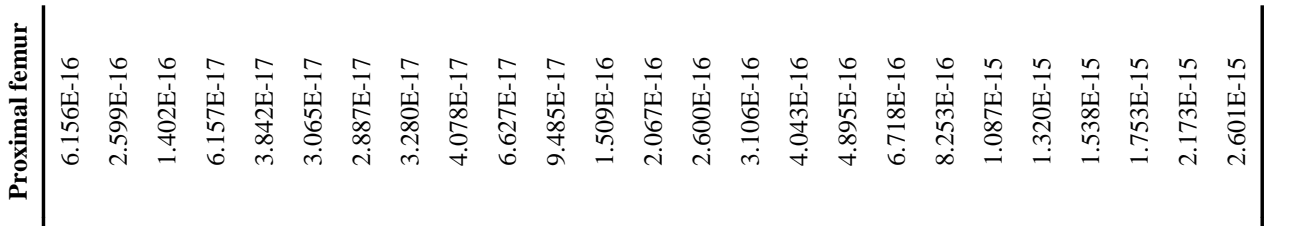

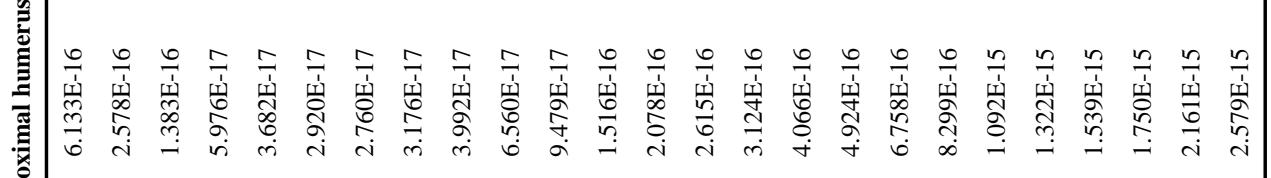

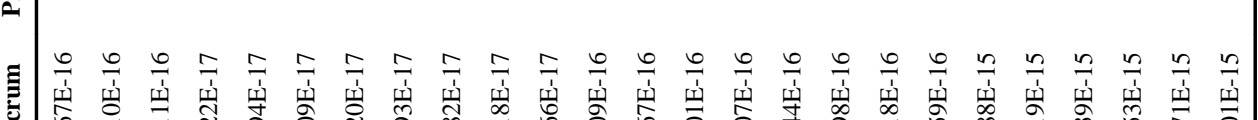

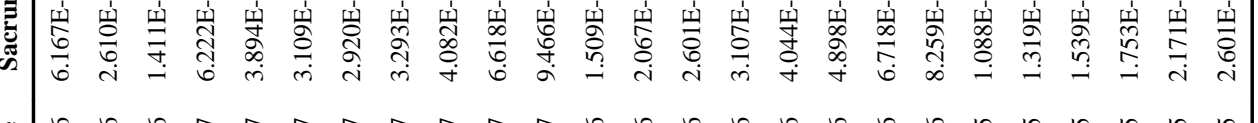

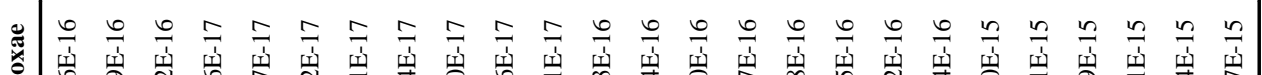

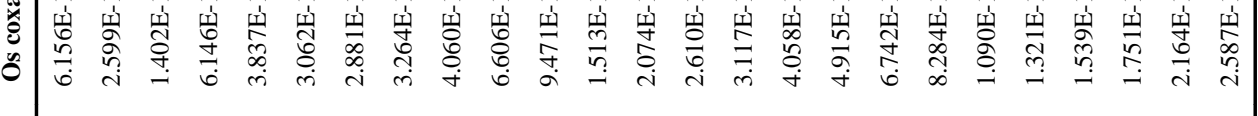

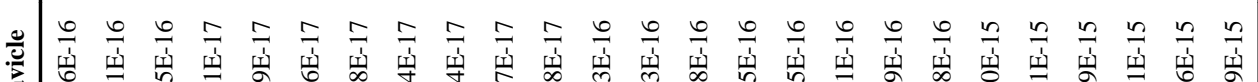

$\dot{\vec{g}}$

$\hat{\sigma}$

$\frac{\overline{0}}{\circ}$

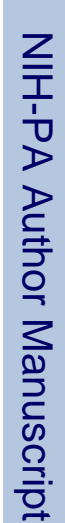

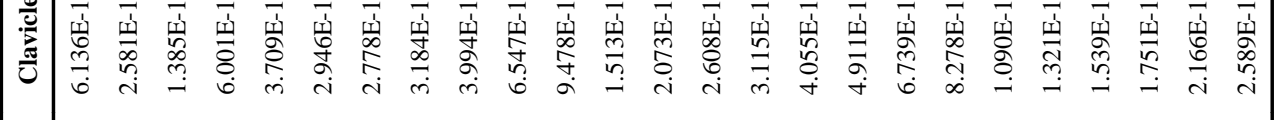

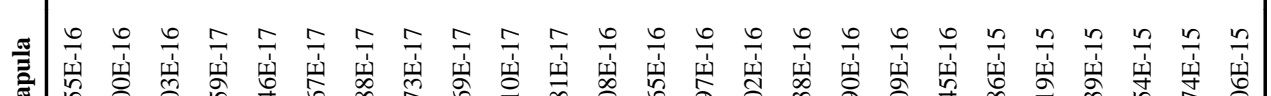

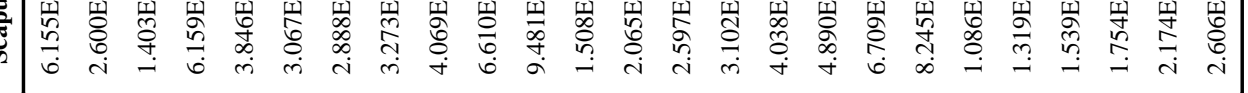

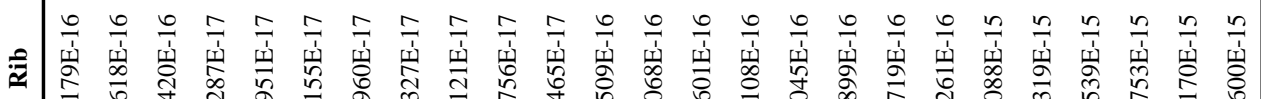

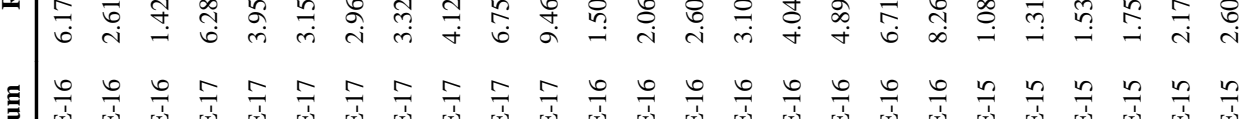

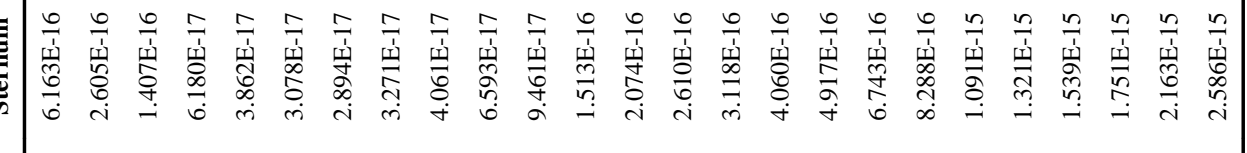

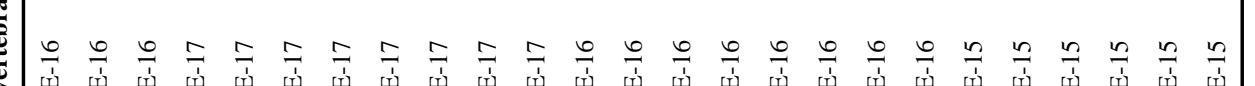

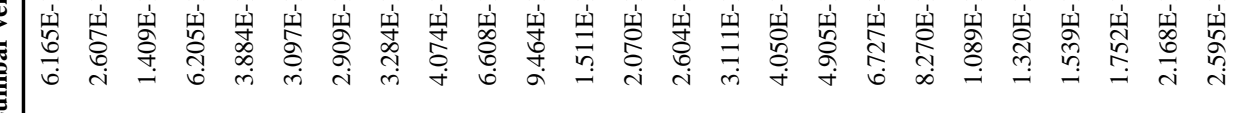

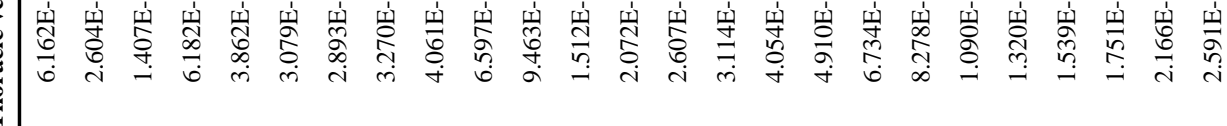

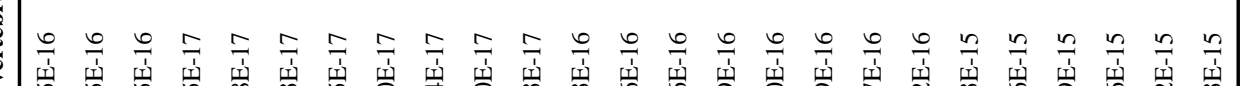

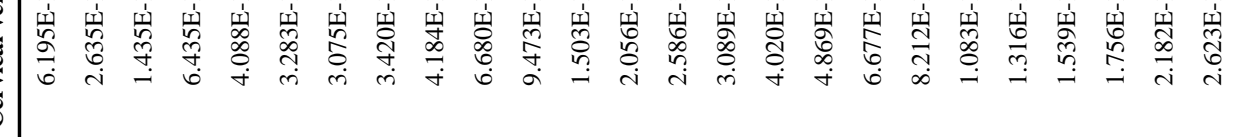

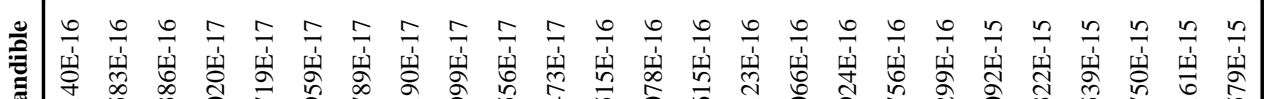

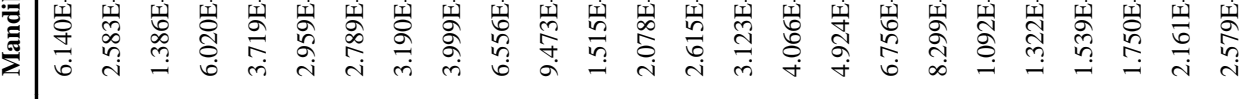
正

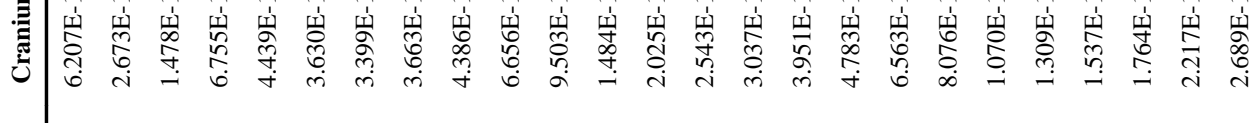

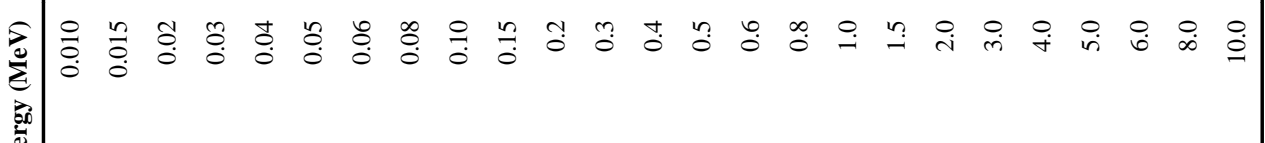
离 


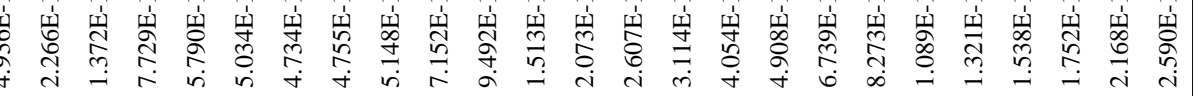
은

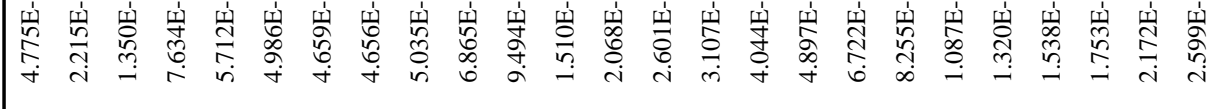

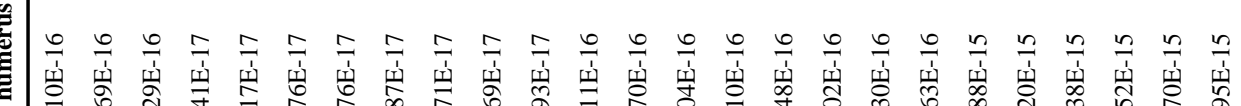

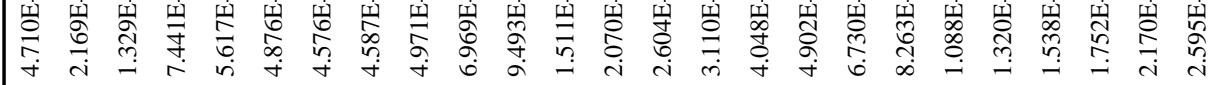

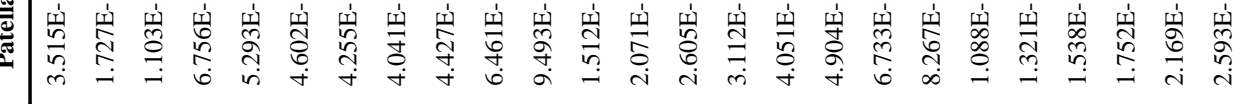

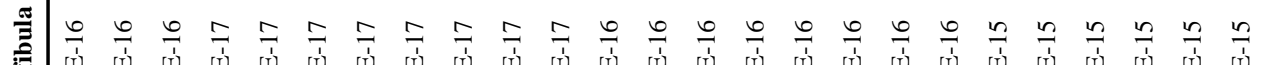

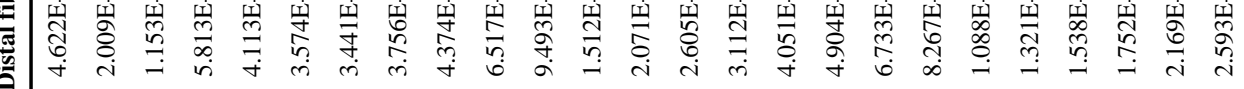

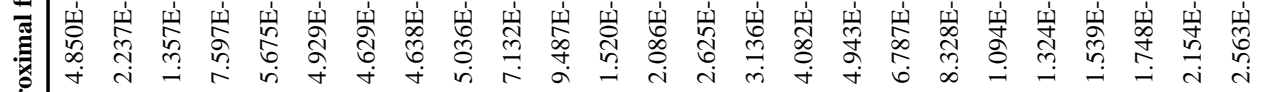

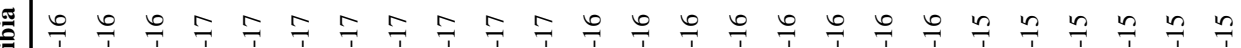

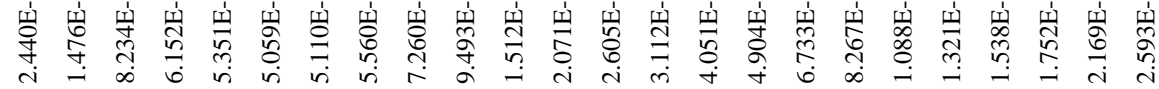

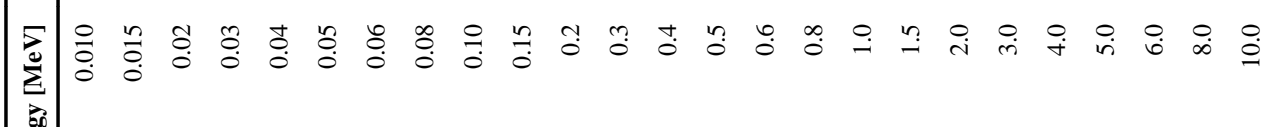
0
0
0
0
0.0
0
0
0
0 
Table 4

Dose response functions for absorbed dose in shallow marrow, $\mathrm{D}$ (TM5o), and active marrow, $\mathrm{D}(\mathrm{AM})$, per photon fluence in the medullary cavities of the long bones, $\Phi$ (meduHary), [Gy $\left.\mathrm{m}^{2}\right]$.

\begin{tabular}{|c|c|c|c|c|c|c|c|c|}
\hline \multirow[t]{2}{*}{ Photon Energy (MeV) } & \multicolumn{6}{|c|}{ Target $-\mathrm{TM}_{50}$} & \multicolumn{2}{|c|}{ Target $-A M$} \\
\hline & Femur & Tibia & Fibula & Humerus & Ulna & Radius & Upper femur & Upper humerus \\
\hline 0.010 & $3.737 \mathrm{E}-16$ & $4.384 \mathrm{E}-16$ & 4.384E-16 & $3.779 \mathrm{E}-16$ & 4.384E-16 & 4.384E-16 & $6.025 \mathrm{E}-16$ & $6.025 \mathrm{E}-16$ \\
\hline 0.015 & $1.526 \mathrm{E}-16$ & $1.790 \mathrm{E}-16$ & $1.789 \mathrm{E}-16$ & $1.543 \mathrm{E}-16$ & $1.790 \mathrm{E}-16$ & $1.789 \mathrm{E}-16$ & $2.477 \mathrm{E}-16$ & $2.477 \mathrm{E}-16$ \\
\hline 0.02 & $7.973 \mathrm{E}-17$ & $9.352 \mathrm{E}-17$ & $9.348 \mathrm{E}-17$ & $8.065 \mathrm{E}-17$ & $9.351 \mathrm{E}-17$ & $9.349 \mathrm{E}-17$ & $1.293 \mathrm{E}-16$ & $1.293 \mathrm{E}-16$ \\
\hline 0.03 & $3.209 \mathrm{E}-17$ & $3.764 \mathrm{E}-17$ & $3.761 \mathrm{E}-17$ & $3.246 \mathrm{E}-17$ & $3.762 \mathrm{E}-17$ & $3.761 \mathrm{E}-17$ & $5.219 \mathrm{E}-17$ & $5.219 \mathrm{E}-17$ \\
\hline 0.04 & $1.929 \mathrm{E}-17$ & $2.257 \mathrm{E}-17$ & $2.253 \mathrm{E}-17$ & $1.951 \mathrm{E}-17$ & $2.260 \mathrm{E}-17$ & $2.260 \mathrm{E}-17$ & $3.040 \mathrm{E}-17$ & $3.040 \mathrm{E}-17$ \\
\hline 0.05 & $1.655 \mathrm{E}-17$ & $1.941 \mathrm{E}-17$ & $1.939 \mathrm{E}-17$ & $1.674 \mathrm{E}-17$ & $1.940 \mathrm{E}-17$ & $1.939 \mathrm{E}-17$ & $2.364 \mathrm{E}-17$ & $2.364 \mathrm{E}-17$ \\
\hline 0.06 & $1.732 \mathrm{E}-17$ & $2.032 \mathrm{E}-17$ & $2.029 \mathrm{E}-17$ & $1.752 \mathrm{E}-17$ & $2.030 \mathrm{E}-17$ & $2.030 \mathrm{E}-17$ & $2.264 \mathrm{E}-17$ & $2264 \mathrm{E}-17$ \\
\hline 0.08 & $2.294 \mathrm{E}-17$ & $2.692 \mathrm{E}-17$ & $2.690 \mathrm{E}-17$ & $2.321 \mathrm{E}-17$ & $2.691 \mathrm{E}-17$ & $2.690 \mathrm{E}-17$ & $2.741 \mathrm{E}-17$ & $2.738 \mathrm{E}-17$ \\
\hline 0.10 & $3.110 \mathrm{E}-17$ & $3.531 \mathrm{E}-17$ & $3.529 \mathrm{E}-17$ & $3.044 \mathrm{E}-17$ & $3.530 \mathrm{E}-17$ & $3.529 \mathrm{E}-17$ & $3.500 \mathrm{E}-17$ & $3.495 \mathrm{E}-17$ \\
\hline 0.15 & $6.135 \mathrm{E}-17$ & $6.202 \mathrm{E}-17$ & $6.392 \mathrm{E}-17$ & 5.992E-17 & $6.199 \mathrm{E}-17$ & $6.198 \mathrm{E}-17$ & $5.129 \mathrm{E}-17$ & $5.129 \mathrm{E}-17$ \\
\hline 0.2 & $9.479 \mathrm{E}-17$ & $9.479 \mathrm{E}-17$ & $9.479 \mathrm{E}-17$ & $9.479 \mathrm{E}-17$ & $9.479 \mathrm{E}-17$ & $9.479 \mathrm{E}-17$ & $9.479 \mathrm{E}-17$ & $9.479 \mathrm{E}-17$ \\
\hline 0.3 & $1.532 \mathrm{E}-16$ & $1.532 \mathrm{E}-16$ & $1.532 \mathrm{E}-16$ & $1.532 \mathrm{E}-16$ & $1.532 \mathrm{E}-16$ & $1.532 \mathrm{E}-16$ & $1.532 \mathrm{E}-16$ & $1.532 \mathrm{E}-16$ \\
\hline 0.4 & $2.105 \mathrm{E}-16$ & $2.105 \mathrm{E}-16$ & $2.105 \mathrm{E}-16$ & $2.105 \mathrm{E}-16$ & $2.105 \mathrm{E}-16$ & $2.105 \mathrm{E}-16$ & $2.105 \mathrm{E}-16$ & $2.105 \mathrm{E}-16$ \\
\hline 0.5 & $2.651 \mathrm{E}-16$ & $2.651 \mathrm{E}-16$ & $2.651 \mathrm{E}-16$ & $2.651 \mathrm{E}-16$ & $2.651 \mathrm{E}-16$ & $2.651 \mathrm{E}-16$ & $2.651 \mathrm{E}-16$ & $2.651 \mathrm{E}-16$ \\
\hline 0.6 & $3.167 \mathrm{E}-16$ & $3.167 \mathrm{E}-16$ & $3.167 \mathrm{E}-16$ & $3.167 \mathrm{E}-16$ & $3.167 \mathrm{E}-16$ & $3.167 \mathrm{E}-16$ & $3.167 \mathrm{E}-16$ & $3.167 \mathrm{E}-16$ \\
\hline 0.8 & $4.124 \mathrm{E}-16$ & $4.124 \mathrm{E}-16$ & $4.124 \mathrm{E}-16$ & $4.124 \mathrm{E}-16$ & $4.124 \mathrm{E}-16$ & $4.124 \mathrm{E}-16$ & $4.124 \mathrm{E}-16$ & $4.124 \mathrm{E}-16$ \\
\hline 1.0 & $4.993 \mathrm{E}-16$ & $4.993 \mathrm{E}-16$ & $4.993 \mathrm{E}-16$ & $4.993 \mathrm{E}-16$ & $4.993 \mathrm{E}-16$ & $4.993 \mathrm{E}-16$ & $4.993 \mathrm{E}-16$ & $4.993 \mathrm{E}-16$ \\
\hline 1.5 & $6.857 \mathrm{E}-16$ & $6.857 \mathrm{E}-16$ & $6.857 \mathrm{E}-16$ & $6.857 \mathrm{E}-16$ & $6.857 \mathrm{E}-16$ & $6.857 \mathrm{E}-16$ & $6.857 \mathrm{E}-16$ & $6.857 \mathrm{E}-16$ \\
\hline 2.0 & $8.407 \mathrm{E}-16$ & $8.407 \mathrm{E}-16$ & $8.407 \mathrm{E}-16$ & $8.407 \mathrm{E}-16$ & $8.407 \mathrm{E}-16$ & $8.407 \mathrm{E}-16$ & $8.407 \mathrm{E}-16$ & $8.407 \mathrm{E}-16$ \\
\hline 3.0 & $1.102 \mathrm{E}-15$ & $1.102 \mathrm{E}-15$ & $1.102 \mathrm{E}-15$ & $1.102 \mathrm{E}-15$ & $1.102 \mathrm{E}-15$ & $1.102 \mathrm{E}-15$ & $1.102 \mathrm{E}-15$ & $1.102 \mathrm{E}-15$ \\
\hline 4.0 & $1.329 \mathrm{E}-15$ & $1.329 \mathrm{E}-15$ & $1.329 \mathrm{E}-15$ & $1.329 \mathrm{E}-15$ & $1.329 \mathrm{E}-15$ & $1329 \mathrm{E}-15$ & $1.329 \mathrm{E}-15$ & $1329 \mathrm{E}-15$ \\
\hline 5.0 & $1.539 \mathrm{E}-15$ & $1.539 \mathrm{E}-15$ & $1.539 \mathrm{E}-15$ & $1.539 \mathrm{E}-15$ & $1.539 \mathrm{E}-15$ & $1.539 \mathrm{E}-15$ & $1.539 \mathrm{E}-15$ & $1.539 \mathrm{E}-15$ \\
\hline 6.0 & $1.743 \mathrm{E}-15$ & $1.743 \mathrm{E}-15$ & $1.743 \mathrm{E}-15$ & $1.743 \mathrm{E}-15$ & $1.743 \mathrm{E}-15$ & $1.743 \mathrm{E}-15$ & $1.743 \mathrm{E}-15$ & $1.743 \mathrm{E}-15$ \\
\hline 8.0 & $2.134 \mathrm{E}-15$ & $2.134 \mathrm{E}-15$ & $2.134 \mathrm{E}-15$ & $2.134 \mathrm{E}-15$ & $2.134 \mathrm{E}-15$ & $2.134 \mathrm{E}-15$ & $2.134 \mathrm{E}-15$ & $2.134 \mathrm{E}-15$ \\
\hline 10.0 & $2.523 \mathrm{E}-15$ & $2.523 \mathrm{E}-15$ & $2.523 \mathrm{E}-15$ & $2.523 \mathrm{E}-15$ & $2.523 \mathrm{E}-15$ & $2.523 \mathrm{E}-15$ & $2.523 \mathrm{E}-15$ & $2.523 \mathrm{E}-15$ \\
\hline
\end{tabular}


Table 5

Kerma factors for the primary tissue components of spongiosa, [Gy $\left.\mathrm{m}^{2}\right]$.

\begin{tabular}{|c|c|c|c|}
\hline Photon Energy (MeV) & Active marrow & Inactive marrow & Trabecular bone \\
\hline 0.010 & $6.141 \mathrm{E}-16$ & $4.411 \mathrm{E}-16$ & $4.294 \mathrm{E}-15$ \\
\hline 0.015 & $2.583 \mathrm{E}-16$ & $1.824 \mathrm{E}-16$ & $1.988 \mathrm{E}-15$ \\
\hline 0.02 & $1.386 \mathrm{E}-16$ & $9.727 \mathrm{E}-17$ & $1.130 \mathrm{E}-15$ \\
\hline 0.03 & $5.985 \mathrm{E}-17$ & $4.267 \mathrm{E}-17$ & $4.991 \mathrm{E}-16$ \\
\hline 0.04 & $3.681 \mathrm{E}-17$ & $2.760 \mathrm{E}-17$ & $2.794 \mathrm{E}-16$ \\
\hline 0.05 & $2.910 \mathrm{E}-17$ & $2.354 \mathrm{E}-17$ & $1.812 \mathrm{E}-16$ \\
\hline 0.06 & $2.738 \mathrm{E}-17$ & $2.373 \mathrm{E}-17$ & $1.298 \mathrm{E}-16$ \\
\hline 0.08 & $3.135 \mathrm{E}-17$ & $2.963 \mathrm{E}-17$ & $8.559 \mathrm{E}-17$ \\
\hline 0.10 & $3.941 \mathrm{E}-17$ & $3.841 \mathrm{E}-17$ & 7.162E-17 \\
\hline 0.15 & $6.515 \mathrm{E}-17$ & $6.552 \mathrm{E}-17$ & $7.538 \mathrm{E}-17$ \\
\hline 0.2 & $9.436 \mathrm{E}-17$ & $9.479 \mathrm{E}-17$ & $9.535 \mathrm{E}-17$ \\
\hline 0.3 & $1.520 \mathrm{E}-16$ & $1.532 \mathrm{E}-16$ & $1.451 \mathrm{E}-16$ \\
\hline 0.4 & $2.086 \mathrm{E}-16$ & $2.105 \mathrm{E}-16$ & $1.969 \mathrm{E}-16$ \\
\hline 0.5 & $2.627 \mathrm{E}-16$ & $2.651 \mathrm{E}-16$ & $2.466 \mathrm{E}-16$ \\
\hline 0.6 & $3.139 \mathrm{E}-16$ & $3.167 \mathrm{E}-16$ & $2.944 \mathrm{E}-16$ \\
\hline 0.8 & $4.087 \mathrm{E}-16$ & $4.124 \mathrm{E}-16$ & $3.827 \mathrm{E}-16$ \\
\hline 1.0 & $4.951 \mathrm{E}-16$ & 4.993E-16 & $4.632 \mathrm{E}-16$ \\
\hline 1.5 & $6.787 \mathrm{E}-16$ & $6.857 \mathrm{E}-16$ & $6.355 \mathrm{E}-16$ \\
\hline 2.0 & $8.344 \mathrm{E}-16$ & $8.407 \mathrm{E}-16$ & $7.838 \mathrm{E}-16$ \\
\hline 3.0 & $1.096 \mathrm{E}-15$ & $1.102 \mathrm{E}-15$ & $1.047 \mathrm{E}-15$ \\
\hline 4.0 & $1.324 \mathrm{E}-15$ & $1.329 \mathrm{E}-15$ & $1.294 \mathrm{E}-15$ \\
\hline 5.0 & $1.540 \mathrm{E}-15$ & $1.539 \mathrm{E}-15$ & $1.535 \mathrm{E}-15$ \\
\hline 6.0 & $1.747 \mathrm{E}-15$ & $1.743 \mathrm{E}-15$ & $1.780 \mathrm{E}-15$ \\
\hline 8.0 & $2.149 \mathrm{E}-15$ & $2.134 \mathrm{E}-15$ & $2.277 \mathrm{E}-15$ \\
\hline 10.0 & $2.561 \mathrm{E}-15$ & $2.523 \mathrm{E}-15$ & $2.807 \mathrm{E}-15$ \\
\hline
\end{tabular}




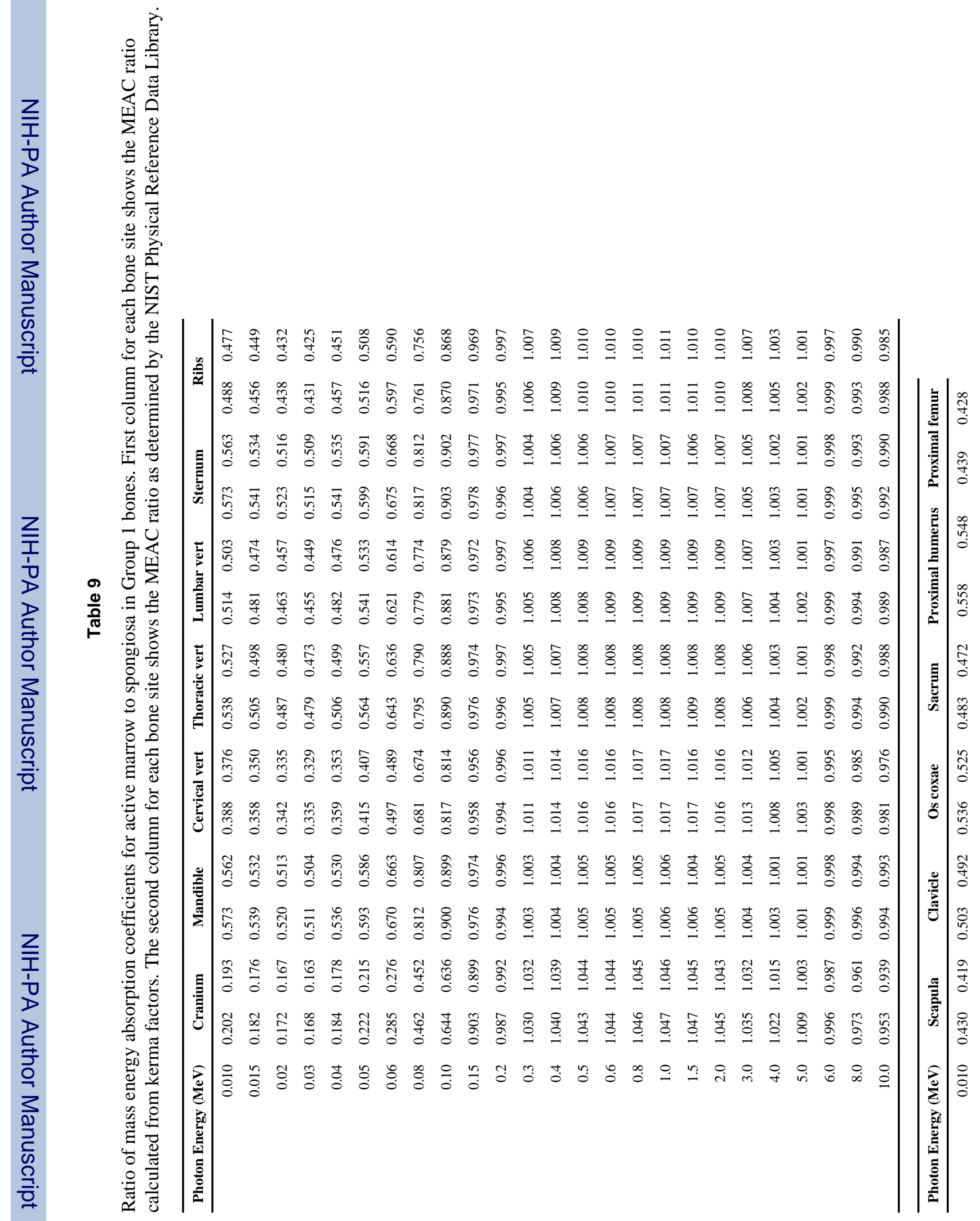




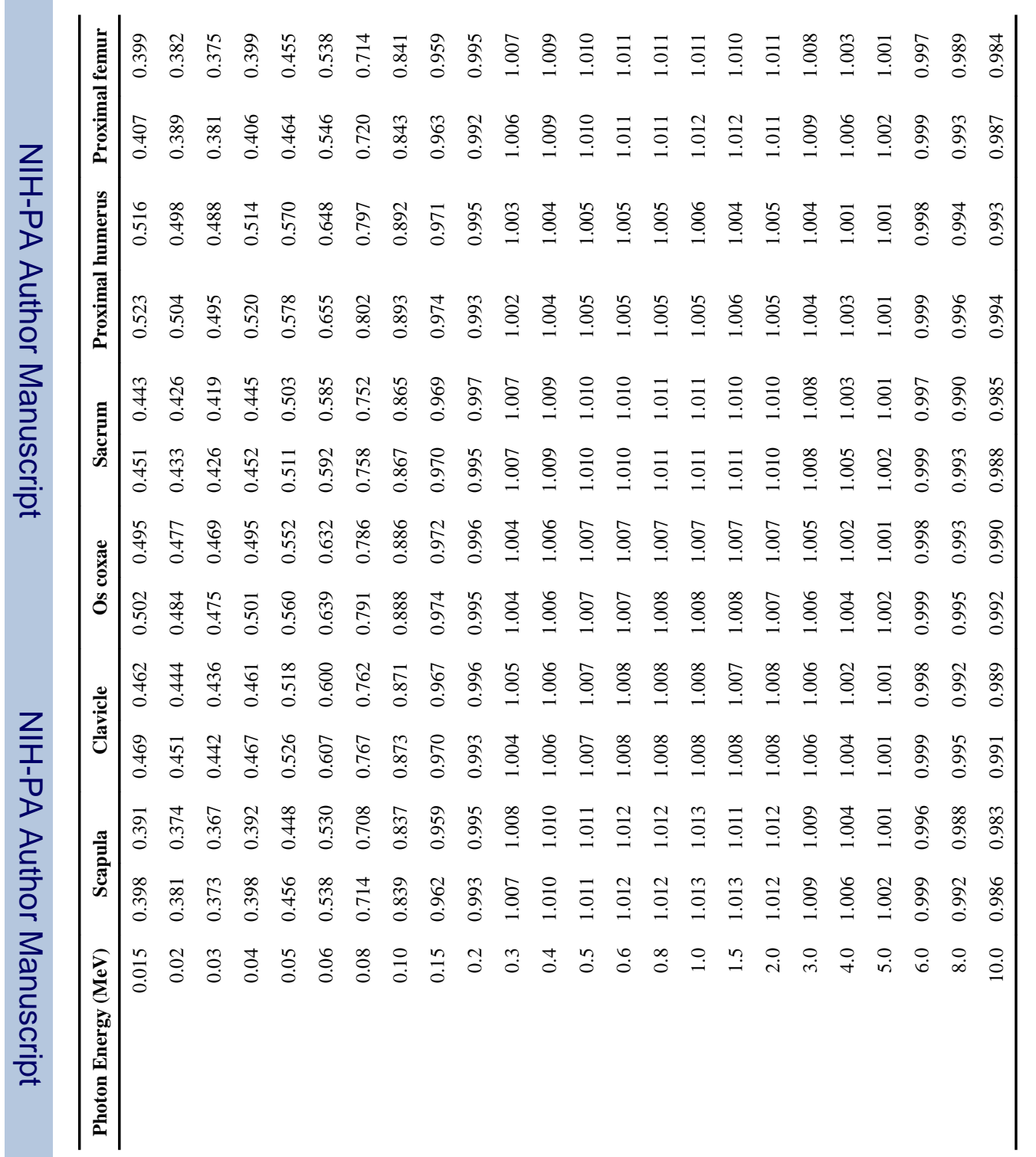




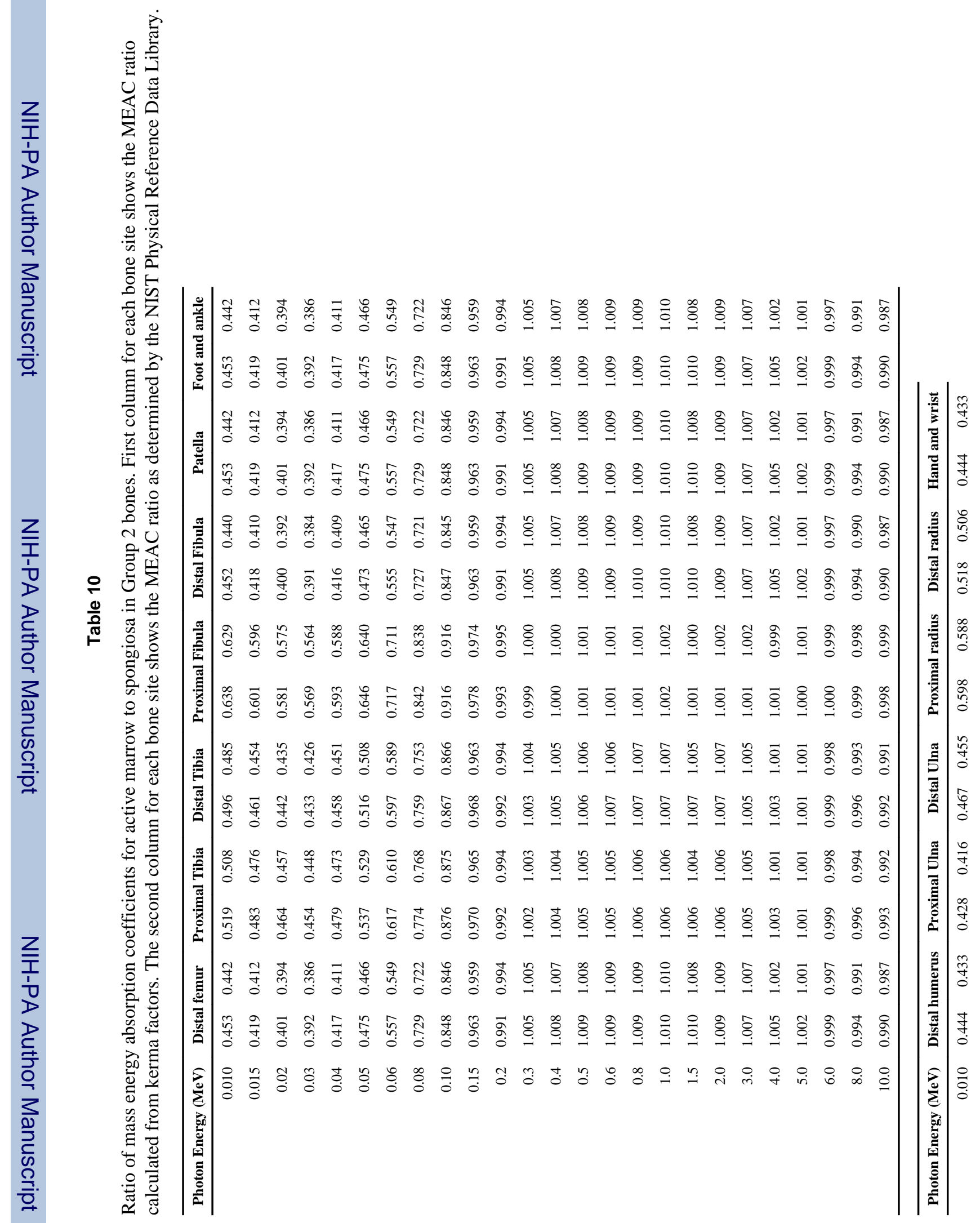




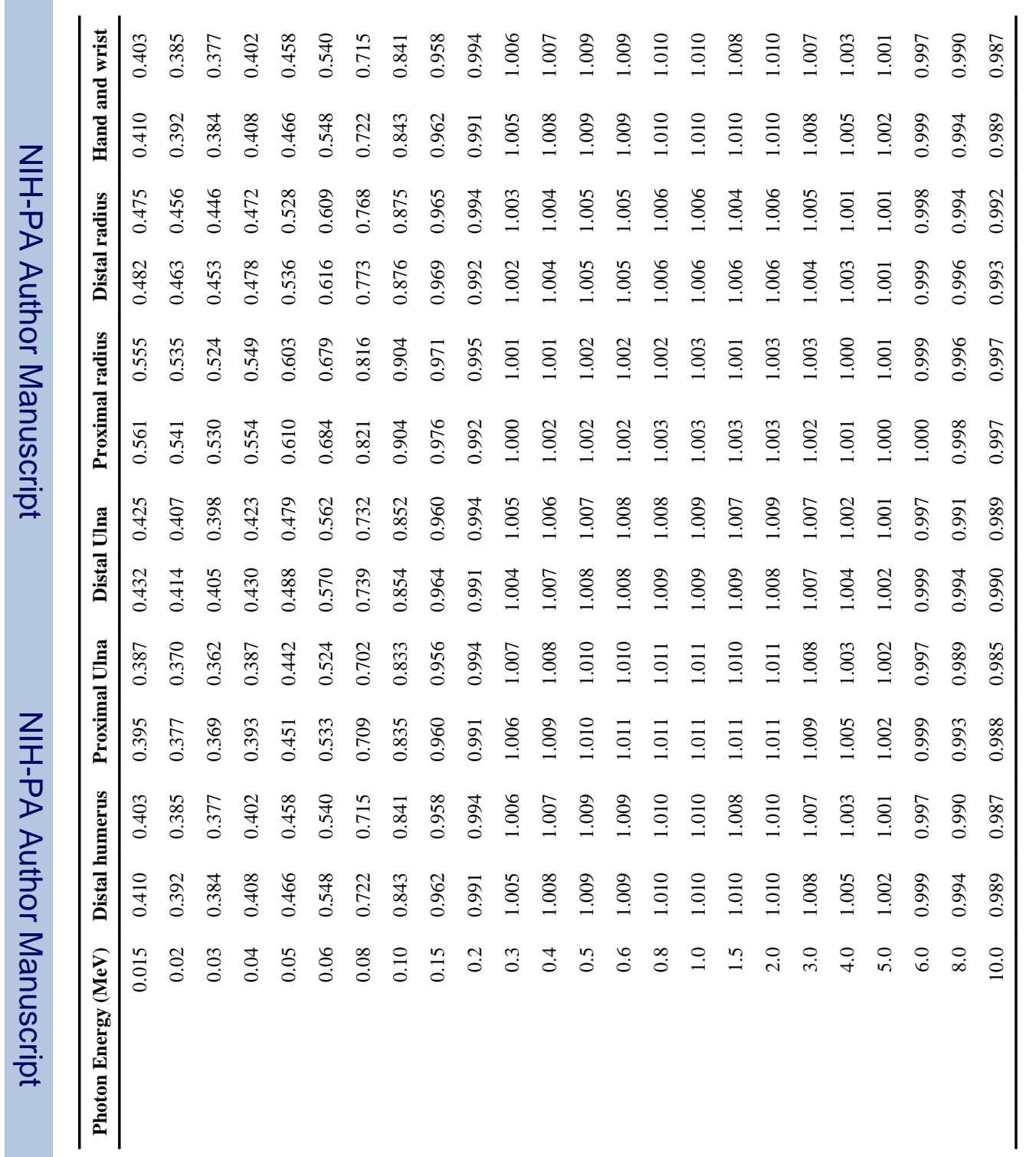




\section{Table 11}

Correlation of the shallow marrow volume fraction and trabecular bone volume fraction with dose enhancement in active marrow. The coefficient of determination is listed for both parameters in the final row.

\begin{tabular}{lrrr}
\hline Bone site & SMVF $_{\% \text { TM }}$ & TBVF $_{\text {\%SP }}$ & Enhancement @ 0.05 MeV \\
\hline Proximal humerus & 8.80 & 9.60 & 0.32 \\
Clavicle & 9.05 & 11.60 & 1.23 \\
Mandible & 8.58 & 8.90 & 1.68 \\
Os Coxae & 12.41 & 10.00 & 5.20 \\
Proximal femur & 14.56 & 15.00 & 5.33 \\
Scapula & 11.77 & 15.30 & 5.39 \\
Sternum & 10.82 & 8.20 & 5.76 \\
Thoracic & 10.12 & 9.40 & 5.81 \\
Lumbar & 11.53 & 10.40 & 6.43 \\
Sacrum & 12.60 & 11.80 & 6.84 \\
Rib & 10.93 & 11.52 & 8.43 \\
Cervical & 17.83 & 17.90 & 12.79 \\
Cranium & 36.75 & 56.20 & 24.72 \\
\hline $\mathrm{R}^{2}$ & 0.91 & 0.82 & -- \\
\hline
\end{tabular}

